\title{
Ag Nanoparticles-enhanced Fluorescence of Terbium-Deferasirox Complexes for the Highly Sensitive Determination of Deferasirox
}

\author{
Jafar Abolhasani, ${ }^{\dagger}$ Roza NADERALI, and Javad HassanZAdEH \\ Department of Chemistry, Tabriz Branch, Islamic Azad University, Tabriz, Iran
}

\begin{abstract}
We describe the effect of different sized gold and silver nanoparticles on the terbium sensitized fluorescence of deferasirox. It is indicated that silver nanostructures, especially $18 \mathrm{~nm} \mathrm{Ag}$ nanoparticles (AgNPs), have a remarkable amplifying effect compared to Au nanoparticles. Based on this observation, a highly sensitive and selective method was developed for the determination of deferasirox. Effects of various parameters like AgNPs and $\mathrm{Tb}^{3+}$ concentration and $\mathrm{pH}$ of media were investigated. Under the optimal conditions, a calibration curve was plotted as the fluorescence intensities versus the concentration of deferasirox in the range of 0.1 to $200 \mathrm{nmol} \mathrm{L}^{-1}$, and detection limit of $0.03 \mathrm{nmol} \mathrm{L}^{-1}$ was obtained. The method has good linearity, recovery, reproducibility and sensitivity, and was satisfactorily applied for the determination of deferasirox in urine and pharmaceutical samples.
\end{abstract}

Keywords Terbium-sensitized fluorescence, deferasirox, Ag nanoparticles, urine

(Received September 7, 2015; Accepted October 13, 2015; Published April 10, 2016)

\section{Introduction}

Iron overload is usually caused by repeated blood transfusions in patients with sickle cell disease and/or chronic anemia. ${ }^{1}$ Also, people with hereditary hemochromatosis and thalassemia major develop secondary iron overload resulting from regular red blood cell transfusions. Excess iron can accumulate as hemosiderin in body organs such as the liver, spleen, and several endocrine organs. Myocardium can result from gradually impaired function of such organs and ultimately lead to death. ${ }^{2}$ Iron chelation therapy with new oral chelator (deferasirox) has shown desired results for avoiding long-term problems. ${ }^{3}$

Deferasirox, 4-[(3Z,5E)-3,5-bis(6-oxocyclohexa-2,4-dien-1ylidene)-1,2,4-triazolidin-1-yl] benzoic acid (Def), as an orally absorbed chelator of $\mathrm{Fe}^{3+}$ is currently used as first-line therapy for thalassemia and transfusional iron overload. ${ }^{4-6}$ Its long half-life (11-19 h depending on dose) provides once-daily dosing which can be present in plasma for $24 \mathrm{~h}$. Single oral administration of $40 \mathrm{mg} \mathrm{kg}^{-1}$ of the drug leads to peak plasma concentration levels of $44.4 \mu \mathrm{g} \mathrm{mL}^{-1}$, approximately $1.5 \mathrm{~h}$ after dosing. ${ }^{7,8}$ Understanding whether Def plasma levels are related to specific characteristics of patients could help physicians to devise a drug regimen better tailored to the individual patient.

Few analytical methods have been reported for the determination of Def in dosage forms or biological fluids, and most of these methods are based on chromatography techniques. ${ }^{1,9,10}$ The electrocatalytic oxidation of Def using cyclic voltammetry, chronoamperometry and electrochemical impedance techniques has also been reported. ${ }^{11}$ Manzoori has recently developed a terbium-sensitized fluorescence method for the determination of Def in biological fluids and tablets. ${ }^{12}$

† To whom correspondence should be addressed.

E-mail: Abolhasani@iaut.ac.ir
Trivalent lanthanide ion complexes with appropriate ligands have been recently applied in useful probes and sensors in chemical and biomedical analyses, due to their specific properties and electronic structure. ${ }^{13,14}$ In these complexes, after excitation of the ligand by irradiation of light at its excitation wavelength, absorbed energy is transferred from the ligand to the central lanthanide ion, and emission will be obtained at its characteristic emission wavelengths. ${ }^{14}$ The upper emitting levels of the lanthanides are more effectively excited by efficient intramolecular energy transfer than the direct form, producing an enhanced fluorescence of the lanthanide by several orders of magnitude.

Lanthanide produce a narrow and long-lived (in the high microsecond or the low millisecond range) luminescence with extremely large Stokes' shift $(\sim 200 \mathrm{~nm})$ and high quantum efficiency. These unique properties of lanthanide's luminescence allow for highly sensitive and selective detection methods.

Lanthanide, especially terbium-sensitized systems, are selective and are widely employed in many different fields of bimolecular and medical research, based on the fluorescence quenching or the enhancement of these chelates. ${ }^{12-29}$ However, a further improvement of sensitivity of these methods would allow the detection of even lower analyte concentrations. Therefore, the combination of amplification strategies with lanthanide luminescence is a highly promising approach.

In recent years, nanoparticles have been introduced in lanthanide luminescence measurements as surface enhancers and could amplify and sensitize them. ${ }^{22-25,27-29} \mathrm{Yu}$ et al. has reported determination of norfloxacin using $\mathrm{Ag}$ nanoparticles (AgNPs) enhanced chemiluminescence sensing of $\mathrm{Tb}^{3+}$-NFLX$\mathrm{Ce}(\mathrm{IV})-\mathrm{Na}_{2} \mathrm{SO}_{3}$ system. ${ }^{23}$ Kamruzzaman et al. applied $\mathrm{Ag}$ nanoparticles enhanced fluorescence sensing of terbium complex for sensitive determination of fluoroquinolones. ${ }^{24}$

In this work, we study metal nanoparticles-enhanced fluorescence sensing of terbium ion complexed with Def. 
$\mathrm{Ag}$ and AuNPs of different sizes were applied and it is observed that $18 \mathrm{~nm}$ AgNPs have remarkably strong enhancement effect on native luminescence of the terbium ions. Furthermore, increases in the fluorescence intensity were proportional to the amount of Def. Based on this effect, a simple, sensitive, efficient, and economical spectrofluorometric method was developed for the determination of Def in urine and pharmaceutical preparations.

\section{Experimental}

\section{Materials and apparatus}

Most of the applied materials were obtained from Merck (Darmstadt, Germany). Terbium(III) chloride hexahydrate $\left(\mathrm{TbCl}_{3} \cdot 6 \mathrm{H}_{2} \mathrm{O}\right)$ was obtained from Acros Organics (Geel, Belgium) and Chloroauric acid $\left(\mathrm{HAuCl}_{4}\right)$ was purchased from Alfa Aesar (Karlsruhe, Germany). Doubly distilled deionized water (obtained from Kasra Co., Tabriz, Iran) was used throughout. A stock standard solution of $100 \mathrm{mg} \mathrm{L}^{-1}$ deferasirox (from Osveh Pharmaceutical Company, Tehran, Iran) was prepared in water and ethanol and stored at $4{ }^{\circ} \mathrm{C}$ in a sealed volumetric flask, and for experiments freshly diluted in water, in order to have less than $2 \%$ ethanol.

Fluorescence spectra and intensity measurements were conducted on a Shimadzu RF-5301 spectrofluorophotometer (Japan) equipped with a quartz cell $(1 \times 1 \mathrm{~cm})$. UV/Vis absorption spectra were obtained with a UV-1800 spectrophotometer (Shimadzu, Japan). Transmission electron microscopy (TEM) images of the NPs were obtained using a Leo 906 transmission electron microscope (Germany).

\section{Preparation of $\mathrm{Au}$ and $\mathrm{Ag}$ nanoparticles of different sizes}

Colloidal AuNPs of approximately 8, 22, $32 \mathrm{~nm}$ in diameter were prepared by the reported procedures. ${ }^{30,31}$ The prepared NPs were stored at $4^{\circ} \mathrm{C}$ and characterized by transmission electron microscopy (TEM). TEM images indicated that average diameters of synthesized gold NPs were about $8 \pm 1.9$, $22 \pm 2.1$ and $32 \pm 2.6 \mathrm{~nm}$.

AgNPs of 18 and $38 \mathrm{~nm}$ in diameter were prepared according to references, ${ }^{32,33}$ respectively. Ag seed NPs with diameter size of about $6 \mathrm{~nm}$ were prepared following the literature procedure. ${ }^{34}$ The resulting NPs were characterized by TEM and statistical analysis revealed that the average diameter of particles was $6 \pm 1.2,18 \pm 1.4$ and $38 \pm 1 \mathrm{~nm}$, respectively. The concentration of synthesized AgNPs $(18 \mathrm{~nm})$ was calculated to be $4.32 \times$ $10^{-7} \mathrm{~mol} \mathrm{~L}^{-1} \cdot 35$

\section{Sample preparation}

Pharmaceutical tablets containing $125 \mathrm{mg}$ deferasirox were prepared from one local drug store in Tabriz. Ten tablets were ground to a fine powder and a 0.34-g aliquot of homogenized powder (about equal to one tablet) was dissolved in ethanol and then filtered through a filter paper and diluted to $250 \mathrm{~mL}$ to obtain a solution containing about $500 \mathrm{mg} \mathrm{L}^{-1}$, according to the label on the tablets. This solution was diluted 100 times with double-distilled water and convenient aliquots from the diluted solution were taken for the determination of Def using the proposed procedure.

Human urine samples containing the drug concerned was obtained by adding a suitable amount of standard Def solution to the drug-free urine. An amount of $1 \mathrm{~mL}$ of this sample was gently mixed with $1 \mathrm{~mL}$ of $0.1 \mathrm{~mol} \mathrm{~L}^{-1} \mathrm{Ba}(\mathrm{OH})_{2}$ and $0.1 \mathrm{~mol} \mathrm{~L}^{-1}$ $\mathrm{ZnSO}_{4}$ solution was put aside at room temperature for $5 \mathrm{~min}$, and then centrifuged ( $2700 \mathrm{~g}$ for $10 \mathrm{~min}$ ). In this condition, any

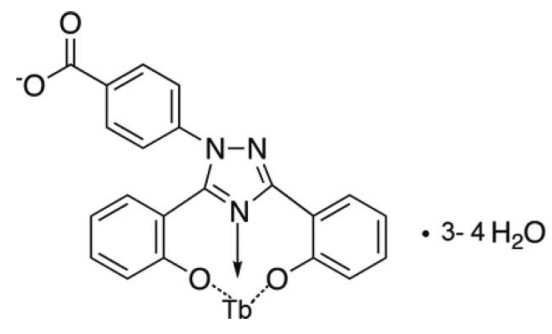

Fig. 1 Proposed chemical structure for the Tb-deferasirox complex.

protein and reducing substances were precipitated to prevent any probable interfering effect. The clear supernatant was diluted to the appropriate concentration. ${ }^{36}$

\section{General procedure}

Fluorescence determination of Def was performed as follows. Briefly, $0.75 \mathrm{~mL}$ Tris (Tris(hydroxymethyl)amino methane) buffer solution $\left(0.1 \mathrm{~mol} \mathrm{~L}^{-1}, \mathrm{pH} 7\right), 0.5 \mathrm{~mL} \mathrm{~Tb} \mathrm{~Tb}^{3+}$ solution $\left(0.01 \mathrm{~mol} \mathrm{~L}^{-1}\right)$ and $120 \mu \mathrm{L}$ prepared $18 \mathrm{~nm}$ AgNPs solution $\left(\sim 4.32 \times 10^{-7} \mathrm{~mol} \mathrm{~L}^{-1}\right)$ were added to $5 \mathrm{~mL}$ calibrated flasks containing a certain amount of deferasirox standard or sample solution. The solutions were diluted to $5 \mathrm{~mL}$ with doubledistilled water and then corresponding fluorescence intensity (at $545 \mathrm{~nm}$ ) were recorded with excitation at $328 \mathrm{~nm}$.

\section{Results and Discussion}

Terbium(III) interaction with deferasirox in the presence of AgNPs

Terbium(III) fluorescence systems are attracting more attention due to their unique emission properties and high quantum yield. $\mathrm{Tb}^{3+}$ solution generates a very weak fluorescence emission because of its weak absorption. In contrast, some ligands can enhance this fluorescence via the energy transfer process. $\mathrm{Tb}^{3+}$ is a good energy acceptor from the lowest triplet state of organic ligand with strong absorption in UV region. The transfer of intermolecular energy from ligands to $\mathrm{Tb}^{3+}$ is a well-known phenomenon. ${ }^{13-15}$

$\mathrm{Tb}^{3+}$ complex with deferasirox has been previously studied by Manzoori et al. ${ }^{12}$ They reported that intense fluorescence can be generated from the Tb-Def complex. Here, we investigate Tb-Def complex formation and its fluorescence characteristics in the presence of $\mathrm{Au}$ and AgNPs. The maximum emission wavelength occurred at 490 and $545 \mathrm{~nm}$ for $\mathrm{Tb}^{3+}$ in the presence of Def, with the maximum excitation wavelength at $328 \mathrm{~nm}$. These emission peaks are according respectively to ${ }^{5} \mathrm{D}_{4} \rightarrow{ }^{7} \mathrm{~F}_{6}$ and ${ }^{5} \mathrm{D}_{4} \rightarrow{ }^{7} \mathrm{~F}_{5}$ transition of $\mathrm{Tb}^{3+}$ ion, which were observed after excitation of Def and energy transfer to $\mathrm{Tb}^{5} \mathrm{D}_{4}$ state. ${ }^{14}$ This is the result of 1:1 complex between $\mathrm{Tb}$ and Def (Fig. 1). ${ }^{12}$ Figure 2a shows the fluorescence of the Tb-Def complex in the presence of different sizes of $\mathrm{Au}$ and AgNPs. It is clear that AuNPs have a decreasing effect on the fluorescence of $\mathrm{Tb}$, probably due to their absorption and inner filter effect. The absorption of AuNPs completely overlap the Tb fluorescence (in $545 \mathrm{~nm}$ ). In contrast, AgNPs can sensibly increase the fluorescence emission intensity of the Tb-Def complex. Moreover, AgNPs with $18 \mathrm{~nm}$ size diameter (TEM image is shown in Fig. 2b) had the most increasing effect. This increasing can lead to high sensitivity in the determination of Def.

On the other hand, the complex formation and its interaction with AgNPs were investigated with UV-Vis absorption studies 
(Fig. 3). The absorption spectra of Def in $\sim 300 \mathrm{~nm}$ shifted to high wavelengths $(325 \mathrm{~nm})$ in the presence of Tb. This indicates complex formation between $\mathrm{Tb}$ and Def. Also, the surface plasmon resonance peak of AgNPs in $\sim 400 \mathrm{~nm}$ decreased in the presence of Def and Tb-Def complex. Investigations on low concentrations of AgNPs showed that Def and its complex with $\mathrm{Tb}$ can even alter the absorption peak of NPs and lead to a sensible red shift (Fig. S1, Supporting Information). This change indicates interaction between the Tb-Def complex and AgNPs. Thus, nanoparticles can modify absorption properties
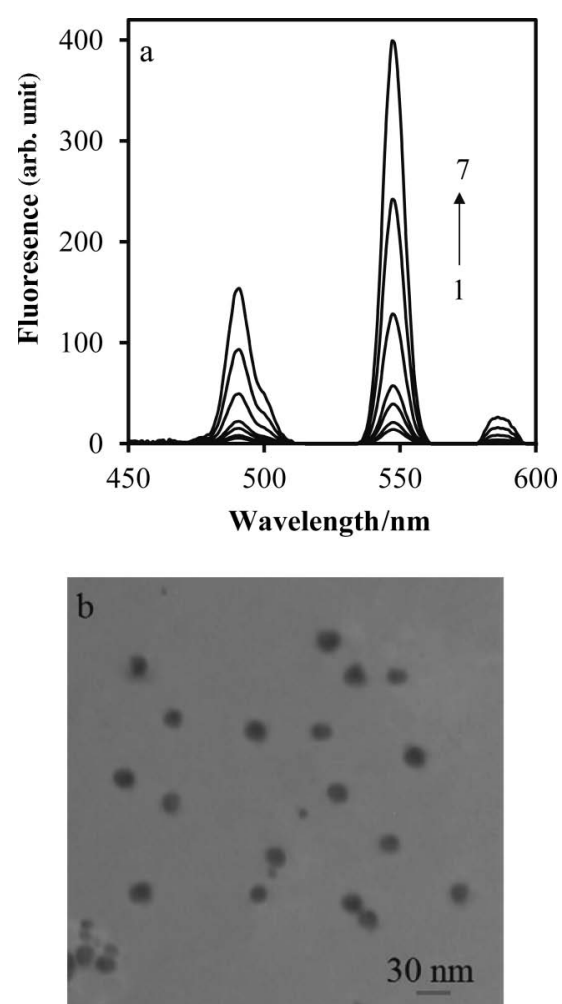

Fig. 2 a) Fluorescence spectra of Tb(III)-Def complex in the absence (4) and presence of (1) $32 \mathrm{~nm}$ AuNPs, (2) $22 \mathrm{~nm}$ AuNPs, (3) $8 \mathrm{~nm}$ AuNPs, (5) 38 nm AgNPs, (6) 6 nm AgNPs, and (7) 18 nm AgNPs [in optimized condition, Def: $50 \mathrm{nmol} \mathrm{L}{ }^{-1}$; b) TEM image of synthesized $18 \mathrm{~nm}$ AgNPs. of fluorophores by changing their free space absorption condition. By exciting the Tb(III)-Def-AgNPs assembly with an external light source, the energy transfers or couples between the electronically excited state and the surface plasmon in metallic nanostructures occurs leading to fluorescence improvement.

With respect to this, we can suggest that the $\mathrm{Tb}(\mathrm{III})$-Def complex may interact with the surface plasmon electrons of AgNPs. Fluorophores are in close vicinity to AgNPs, and the increased electric field nearby NPs enhance the absorption of light by the Tb-Def-AgNPs system..$^{22,23}$ Increasing of local excitation fields around the edges of particles also may be the reason for the observed enhancement effect of AgNPs on the luminescence of the Tb-Def complex. ${ }^{22}$

Thus, as indicated in Scheme 1, when Tb-Def complexes on the surface of AgNPs are excited by an external light source, the energy of the electronically excited state was transferred or coupled to the surface plasmon of AgNPs. Then, luminescence was emitted by the AgNPs-Tb-Def system with the same spectral characteristics of $\mathrm{Tb}$ emission.

\section{Optimization of experimental conditions}

The effect of $\mathrm{pH}$ on the fluorescence intensity of Tb-DefAgNPs was investigated (Fig. 4a). The maximum fluorescence intensity was obtained at $\mathrm{pH} 7$, which is optimum $\mathrm{pH}$ value for Tb-Def complex formation. Above this $\mathrm{pH}$, the hydroxylation of $\mathrm{Tb}^{3+}$ ions would occur. In contrast, lower $\mathrm{pHs}$ would probably protonated the hydroxyl groups of Def that destroy its complex

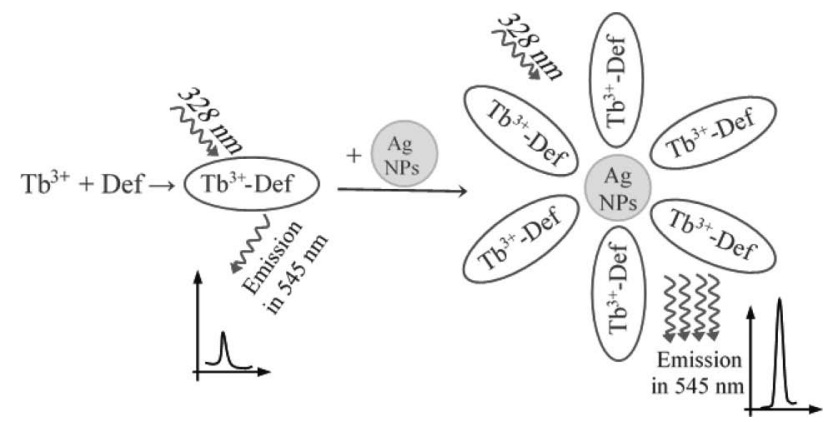

Scheme 1 Schematic diagram of AgNPs enhanced luminescence of $\mathrm{Tb}^{3+}$-Def complex.

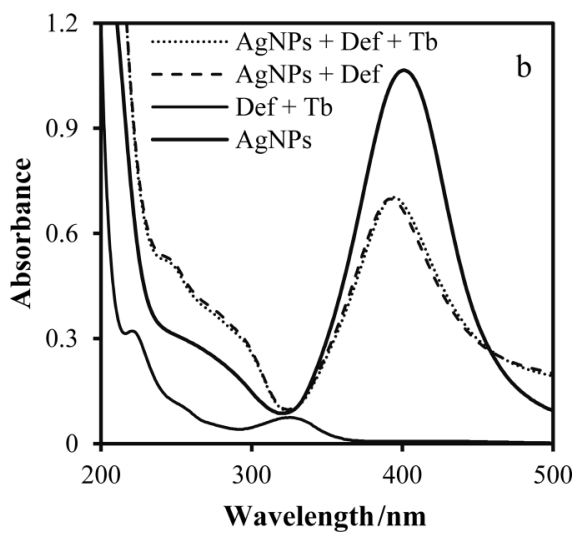

Fig. 3 a) UV-vis absorption spectra of deferasirox, $\mathrm{Tb}^{3+}$ and their complexes; b) UV-vis absorption spectra of AgNPs in the absence and presence of $\mathrm{Tb}^{3+}$ and deferasirox [in Tris buffer (pH 7), Def: $\left.10^{-5} \mathrm{~mol} \mathrm{~L}^{-1}, \mathrm{~Tb}^{3+}: 2 \times 10^{-5} \mathrm{~mol} \mathrm{~L}^{-1}\right]$. 

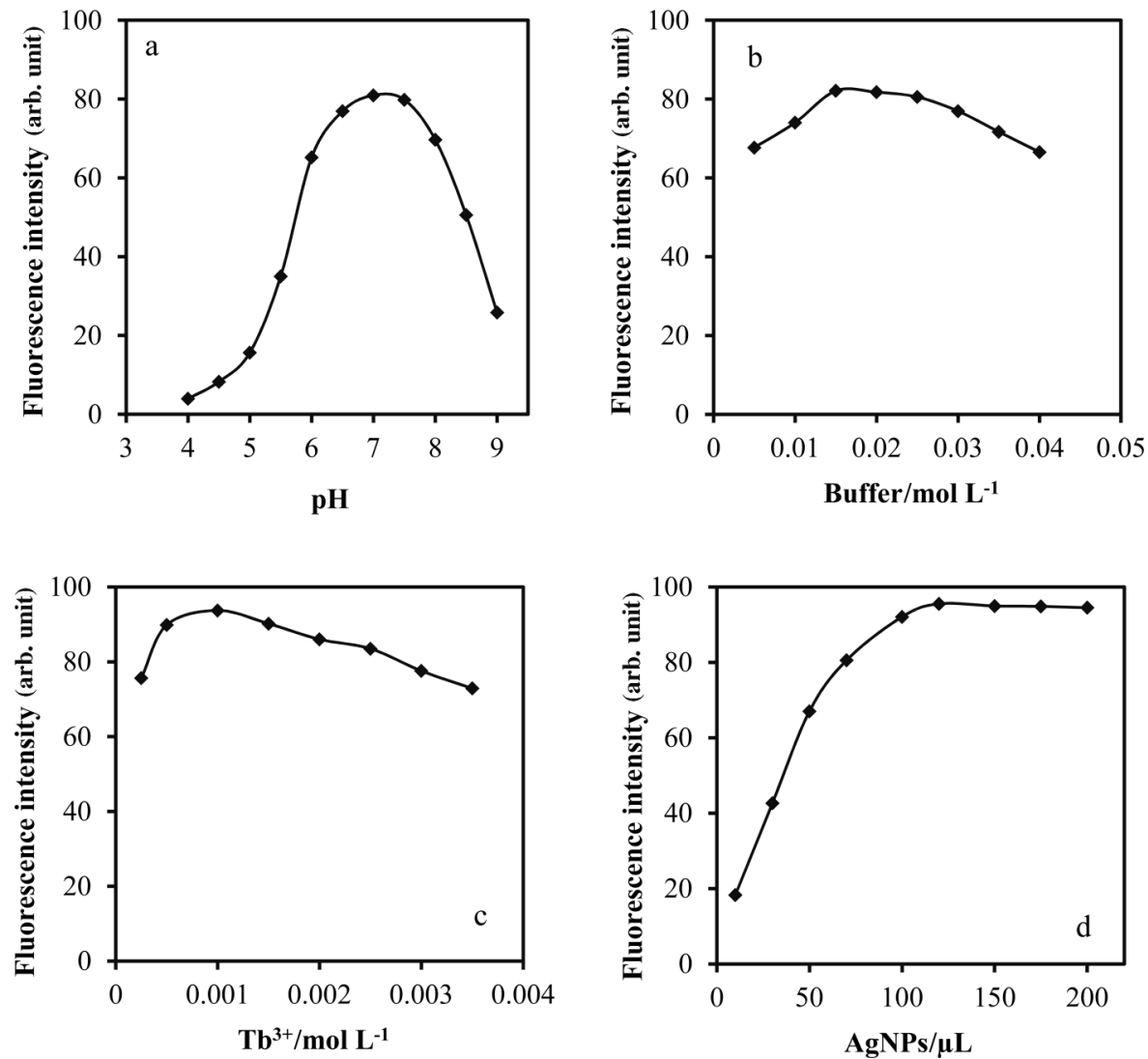

Fig. 4 Effect of a) $\mathrm{pH}\left[\mathrm{Tb}^{3+}: 0.0025 \mathrm{~mol} \mathrm{~L}^{-1}\right.$, deferasirox: $10^{-5} \mathrm{~mol} \mathrm{~L}^{-1}$, Tris-HCl: $0.025 \mathrm{~mol} \mathrm{~L}^{-1}$ and AgNPs: $100 \mu \mathrm{L}]$; b) buffer concentration $\left[\mathrm{Tb}^{3+}: 0.0025 \mathrm{~mol} \mathrm{~L}^{-1}\right.$, deferasirox: $10^{-5} \mathrm{~mol} \mathrm{~L}^{-1}, \mathrm{pH} 7$ and AgNPs: $100 \mu \mathrm{L}$ ]; c) $\mathrm{Tb}^{3+}$ concentration [deferasirox: $10^{-5} \mathrm{~mol} \mathrm{~L}^{-1}$, Tris-HCl: $0.015 \mathrm{~mol} \mathrm{~L}^{-1}, \mathrm{pH} 7$ and AgNPs: $100 \mu \mathrm{L}]$ and d) AgNPs concentration $\left[\mathrm{Tb}^{3+}: 0.001 \mathrm{~mol} \mathrm{~L}^{-1}\right.$, deferasirox: $10^{-5} \mathrm{~mol} \mathrm{~L}^{-1}$, Tris-HCl: $0.001 \mathrm{~mol} \mathrm{~L}^{-1}$ and $\mathrm{pH}$ 7] on the fluorescence intensity of $\mathrm{Tb}^{3+}$-Def-AgNPs system.

with $\mathrm{Tb}$. In order to adjust $\mathrm{pH}$ to 7 , several buffers (phosphate, carbonate, acetate, and Tris) were tested. In the presence of phosphate buffer, fluorescence was remarkably decreased, probably due to the complex formation between $\mathrm{Tb}^{3+}$ and phosphate ions. Other buffers can enhance Tb fluorescence by joining to the Tb-Def complex and replacing $\mathrm{H}_{2} \mathrm{O}$ molecules. $\mathrm{H}_{2} \mathrm{O}$ can decrease $\mathrm{Tb}$ fluorescence by non-radiative energy absorption through $\mathrm{O}-\mathrm{H}$ vibrations. Tris buffer caused the highest fluorescence of all the studied buffers, due to greater tendency of Tris molecules to Tb.

Next, the effect of the concentration of Tris buffer on the fluorescence signal was investigated. It can be seen in Fig. 4b that the fluorescence of Tb-Def-AgNPs improves when increasing the Tris concentration up to $0.015 \mathrm{~mol} \mathrm{~L}^{-1}$ and then decreases gradually. Tris molecules in lower concentrations do not completely bind to terbium ions, leading to a decrease in fluorescence.

The effect of concentration of fluorescent reagent $\left(\mathrm{Tb}^{3+}\right)$ was studied in the range of $3 \times 10^{-3}-35 \times 10^{-3} \mathrm{~mol} \mathrm{~L}^{-1}$ (Fig. 4c). The maximum sensitivity was obtained in $1 \times 10^{-3} \mathrm{~mol} \mathrm{~L}^{-1} \mathrm{~Tb}^{3+}$. Below this concentration, there is not a sufficient amount of $\mathrm{Tb}^{3+}$ for complex formation with Def.

Finally, effect of the amount of AgNPs on the fluorescence intensities was studied (Fig. 4d). The fluorescence intensity of the $\mathrm{Tb}^{3+}$-DFX system reached a maximum when $120 \mu \mathrm{L}$ of synthesized AgNPs solution was added.

Under the obtained optimum conditions, the fluorescence intensity was stable for about $100 \mathrm{~min}$ after addition of all
Table 1 Interference of different ions on the determination of deferasirox in optimum conditions with $1 \mu \mathrm{mol} \mathrm{L}^{-1}$ Def

\begin{tabular}{lrc}
\hline \multicolumn{1}{c}{ Coexisting substance } & $\begin{array}{c}\text { Tolerance } \\
\text { limit }\end{array}$ & $\begin{array}{c}\Delta F \% \\
\text { variation }\end{array}$ \\
\hline $\mathrm{Na}^{+}, \mathrm{K}^{+}, \mathrm{Ca}^{2+}, \mathrm{Cu}^{2+}, \mathrm{Cl}^{-}, \mathrm{NO}_{3}{ }^{-}$ & 6000 & $<2.6 \%$ \\
$\mathrm{Mg}^{2+}, \mathrm{Al}^{3+}, \mathrm{PO}_{4}^{3-}, \mathrm{Mn}^{2+}, \mathrm{SO}_{4}^{2-}, \mathrm{CO}_{3}^{2-}$, & 2500 & $<3.1 \%$ \\
$\mathrm{HCO}_{3}{ }^{2-}, \mathrm{CH}_{3} \mathrm{COO}$ & & \\
$\mathrm{Fe}^{2+}, \mathrm{Fe}^{3+}, \mathrm{Zn}^{2+}, \mathrm{Cr}^{3+}$ & 500 & $<1.9 \%$ \\
$\mathrm{Vitamins}_{1}, \mathrm{~B}_{2}$, alanine, lactose, & 1500 & $<2.3 \%$ \\
$\quad$ sucrose, L-leucine, fructose, glycine & & \\
Glucose, ascorbic acid, oxalate, uric acid & 500 & $<4.0 \%$ \\
Citrate, $\mathrm{Hg}^{2+}$ & 200 & $<3.9 \%$ \\
Glutathione, cysteine, $\mathrm{Ni}^{2+}, \mathrm{I}^{-}, \mathrm{Pb}^{2+}, \mathrm{Cd}^{2+}$ & 100 & $<4.3 \%$ \\
\hline
\end{tabular}

reagents because of rapid complex formation reaction between $\mathrm{Tb}^{3+}$ and Def. A time of $5 \mathrm{~min}$ was selected as the fixed time for all fluorescence intensity measurements.

The experiments show that temperature and also addition order of reagents did not have a significant effect on the fluorescence intensity. Therefore, all experiments were carried out at room temperature $\left(25^{\circ} \mathrm{C}\right)$.

\section{Study of interferences}

In order to test the interference effect of some potentially interfering substances on the fluorescence intensity of Tb-Def- 

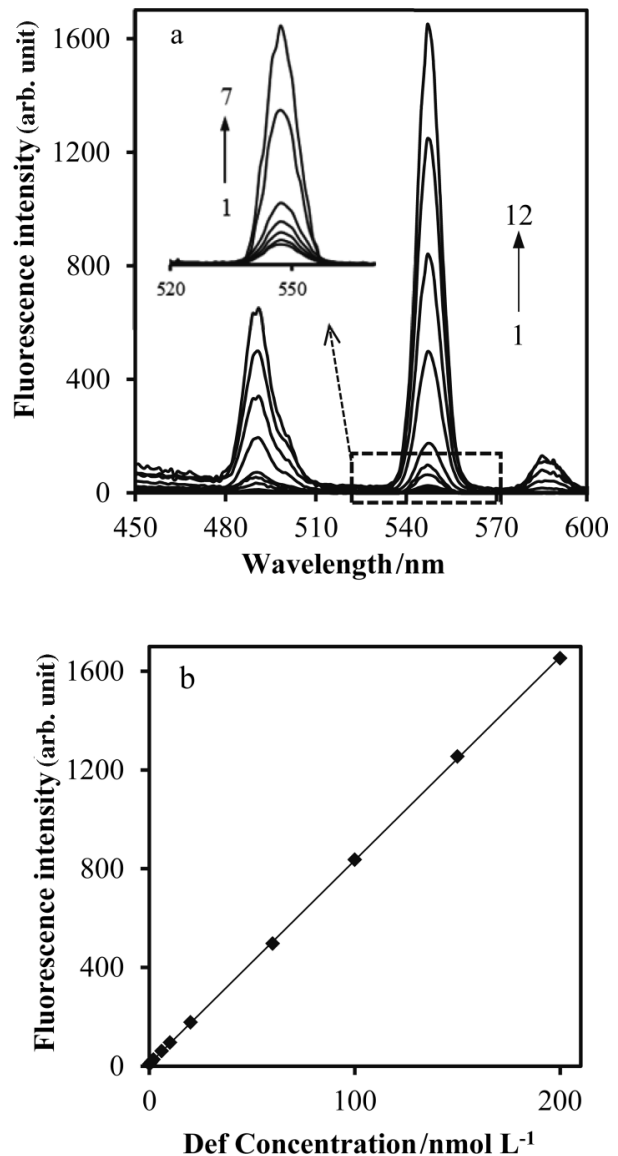

Fig. 5 a) Fluorescence spectra of $\mathrm{Tb}^{3+}$-Def-AgNPs system with various concentrations of Def and b) corresponding calibration graph [optimized condition, 1 - 12: 0.1, 0.2, 0.6, 1, 2, 6, 10, 20, 60, 100, 150, $200 \mathrm{nmol} \mathrm{L}{ }^{-1}$ Def, respectively].

AgNPs, increasing amounts of these species were added into a solution of $50 \mathrm{nmol} \mathrm{L}^{-1}$ Def and determination was performed under the optimal conditions. The tolerable concentration ratios for interferences in relative error of $<5 \%$ are shown in Table 1. As can be seen, the amounts of most of the potentially interfering species in real samples are below their tolerable levels, so there would be no interferences from these species in Def determination. On the other hand, diluting urine samples eliminated the slight interference of uric acid.

\section{Analytical figures of merit}

The fluorescence intensity of the proposed system is proportional to the Def concentration and based on this phenomenon a sensitive method was developed for the determination of Def. In optimum conditions, the fluorescence intensity $(F)$ was plotted versus the concentration of Def in $\mu \mathrm{mol} \mathrm{L}^{-1}(C)$. The calibration graph and corresponding fluorescence spectra are shown in Fig. 5. The linear dynamic range was $0.1-200 \mathrm{nmol} \mathrm{L}^{-1}$, with a detection limit $(3 \sigma)$ of $0.03 \mathrm{nmol} \mathrm{L}^{-1}$. The regression equation was: $F=82.42 C+99.5$ with a correlation coefficient of 0.9999 . The relative standard deviations (RSD\%) for five replicate determinations of 1,30 and $150 \mathrm{nmol} \mathrm{L}^{-1}$ Def were 3.22, 1.86 and $1.34 \%$, respectively. These results indicate that this terbium-AgNPs system has good linearity, relatively high sensitivity and adequate precision.
Analysis of real samples

The procedure was easily applied to the determination of Def in pharmaceutical and human urine samples (Tables S1 and S2, Supporting Information). In order to validate the method, known quantities of Def were added into the samples before the pretreatment step, and then the samples were prepared and analyzed according to the general procedure (Tables S1 and S2, Supporting Information). Statistical analysis of these results using Student t-test showed that there are no significant differences between the added and found values.

\section{Conclusions}

The effect of Au and AgNPs of different size was studied on the fluorescence emission of the deferasirox- $\mathrm{Tb}(\mathrm{III})$ complex. AgNPs with diameter size of $18 \mathrm{~nm}$ indicated the best positive effect. Based on this effect, a sensitive method for the simple determination of deferasirox has been developed. The method was applied for the determination of deferasirox in pharmaceutical and spiked human urine samples without complex pretreatment.

\section{Supporting Information}

Supporting Information includes results for the determination of Def in the real samples (Tables S1 and S2). This material is available free of charge on the Web at http://www.jsac.or.jp/ analsci/.

\section{References}

1. H. Pligoropoulou, A. Vonaparti, and I. Panderi, $J$. Chromatogr. B, 2012, 893-894, 114.

2. N. F. Olivieri, N. Engl. J. Med., 1999, 341, 99.

3. J. J. Meerpohl, G. Antes, G. Rücker, N. Fleeman, E. Motschall, C. M. Niemeyer, and D. Bassler, Cochrane Database SystRev.2012;2:CD007476.doi:10.1002/14651858. CD007476.pub2.

4. M. Otto-Duessel, M. Aguilar, N. Hanspeter, R. Moats, and J. C. Wood, Exp. Hematol., 2007, 35, 1069.

5. E. Wimazal, T. Nosslinger, C. Baumgartner, W. R. Sperr, M. Pfeilstocker, and P. Valent, Eur. J. Clin. Invest., 2009, 39, 406

6. G. Metzgeroth, D. Dinter, B. Schultheis, A. Dorn-Beineke, K. Lutz, O. Leismann, R. Hehlmann, and J. Hastka, Ann. Haematol., 2009, 88, 301.

7. A. S. Ibrahim, T. Gebermariam, Y. Fu, L. Lin, M. I. Husseiny, S. W. French, J. Schwartz, C. D. Skory, J. E. Edwards, and B. J. Spellberg, J. Clin. Invest., 2007, 117, 2649.

8. F. Mattioli, M. Puntoni, V. Marini, C. Fucile, G. Milano, L. Robbiano, S. Perrotta, V. Pinto, A. Martelli, and G. L. Forni, Eur. J. Haematol., 2015, 94, 310.

9. G. J. M. Bruin, T. Faller, H. Wiegand, A. Schweitzer, H. Nick, J. Schneider, K. O. Boernsen, and F. Waldmeier, Drug Metab. Dispos., 2008, 36, 2523.

10. M. C. Rouan, C. Buffet, L. Masson, F. Marfil, H. Humbert, and G. Maurer, J. Chromatogr. B, 2001, 754, 45.

11. M. Hajjizadeh, A. Jabbari, H. Heli, A. A. MoosaviMovahhedi, A. Shafiee, and K. Karimian, Anal. Biochem., 2008, 373, 337.

12. J. L. Manzoori, A. Jouyban, M. Amjadi, V. Panahi-Azar, 
E. Tamizi, and J. Vaez-Gharamaleki, Luminescence, 2011, 26, 244

13. J. P. Leonard and T. Gunnlaugsson, J. Fluoresc., 2005, 15, 585.

14. A. Dossing, Eur. J. Inorg. Chem., 2005, 8, 1425.

15. A. Gomez-Hens and M. P. Aguilar-caballos, TrAC, Trends Anal. Chem., 2002, 21, 131.

16. A. S. Ndao, A. Buzady, J. Erostyak, and I. Hornyak, J. Fluoresc., 2008, 18, 649.

17. A. V. Yegorova, Y. V. Scripinets, A. Duerkop, A. A. Karsyov, V. P. Antonovich, and O. S. Wolfbeis, Anal. Chim. Acta, 2007, 584, 260.

18. A. Jouyban, M. Shaghaghi, J. L. Manzoori, J. Soleymani, and J. Vaez-Gharamaleki, Iranian J. Pharm. Res., 2011, 10, 695.

19. F. Yu, L. Li, and F. Chen, Anal. Chim. Acta, 2007, 610, 257.

20. A. Ruiz-Medina, E. J. Llorent-Martinez, P. Ortega-Barrales, and M. L. F. D. Cordova, Appl. Spectrosc. Rev., 2011, 46, 561.

21. S. M. Z. Al-Kindy, Z. Al-Harasi, F. E. O. Suliman, A. Al-Hamadi and A. Pillay, J. Fluoresc., 2009, 19, 249.

22. A.-M. Alam, M. Kamruzzaman, S. H. Lee, Y. H. Kim, S. Y. Kim, G. M. Kim, H. J. Jo, and S. H. Kim, Microchim. Acta, 2012, 176, 153.

23. X. Yu, Z. Jiang, Q. Wang, and Y. Guo, Michrochim. Acta, 2010, 171, 17.

24. M. Kamruzzaman, A. M. Alam, S. H. Lee, Y. H. Suh, Y. H.
Kim, G. Y. Kim, and S. H. Kim, Michrochim. Acta, 2011, 174, 353.

25. M. N. Khan, J. Shah, M. Rasul Jan, and S. H. Lee, J. Fluoresc., 2013, 23, 161.

26. E. J. Lorent-Martınez, J. Jimenez-Lopez, I. DelgadoBlanca, P. Ortega-Barrales, and A. Ruiz-Medina, Anal. Lett., 2013, 46, 1816.

27. S. H. Lee, S. M. Wabaidur, Z. A. Alothman, and S. M. Alam, Luminescence, 2011, 26, 768.

28. H. C. Zhao, F. Ding, X. Wang, H. Ju, A. Li, and L. P. Jin, Spectrochim. Acta, Part A, 2008, 70, 332.

29. M. Kamruzzaman, A. M. Alam, K. M. Kim, S. H. Lee, Y. S. Suh, Y. H. Kim, S. H. Kim, and S. H. Oh, J. Nanosci. Nanotechnol., 2012, 12, 6125.

30. E. G. Zisimopoulos, G. Z. Tsogas, D. L. Giokas, N. I. Kapakoglou, and A. G. Vlessidis, Talanta, 2009, 79, 893.

31. G. Frens, Nat. Phys. Sci., 1973, 241, 20.

32. J. Z. Guo, H. Cui, W. Zhou, and W. Wang, J. Photochem. Photobiol., A, 2008, 193, 89.

33. H. Chen, F. Gao, R. He, and D. X. Cui, J. Colloid Interface Sci., 2007, 315, 158.

34. D. Aherne, D. M. Ledwith, and M. Gara, Adv. Funct. Mater., 2008, 18, 2005.

35. J. R. Navarro and M. H. Werts, Analyst, 2013, 138, 583.

36. J. Abolhasani and J. Hassanzadeh, Luminescence, 2014, 29 , 1053. 